\title{
Myeloperoxidase and Septic Conditions Disrupt Sphingolipid Homeostasis in Murine Brain Capillaries In Vivo and Immortalized Human Brain Endothelial Cells In Vitro
}

\author{
Madeleine Goeritzer ${ }^{1,2}$, Eva Bernhart ${ }^{1}$, Ioanna Plastira ${ }^{1}\left(\mathbb{D}\right.$, Helga Reicher $^{1}$, Christina Leopold ${ }^{1}$, \\ Thomas O. Eichmann 2,3,4 , Gerald Rechberger ${ }^{2,3,4}$, Corina T. Madreiter-Sokolowski ${ }^{1,5}$, \\ Jürgen Prasch ${ }^{1}{ }^{\circledR}$, Philipp Eller ${ }^{6}$, Wolfgang F. Graier ${ }^{1}{ }^{\circledR}$, Dagmar Kratky ${ }^{1,2}{ }^{\oplus}$, Ernst Malle ${ }^{1}$ and \\ Wolfgang Sattler 1,2,4,* \\ 1 Division of Molecular Biology and Biochemistry, Gottfried Schatz Research Center, Medical University of \\ Graz, Graz 8010, Austria; madeleine.goeritzer@medunigraz.at (M.G.); eva.bernhart@medunigraz.at (E.B.); \\ ioanna.plastira@medunigraz.at (I.P.); helga.reicher@medunigraz.at (H.R.); \\ christina.leopold@medunigraz.at (C.L.); corina.madreiter@hest.ethz.ch (C.T.M.-S.); \\ j.prasch@medunigraz.at (J.P.); wolfgang.graier@medunigraz.at (W.F.G.); \\ dagmar.kratky@medunigraz.at (D.K.); ernst.malle@medunigraz.at (E.M.) \\ 2 BioTechMed-Graz, Graz 8010, Austria; thomas.eichmann@uni-graz.at (T.O.E.); \\ gerald.rechberger@uni-graz.at (G.R.) \\ 3 Institute of Molecular Biosciences, University of Graz, Graz 8010, Austria \\ 4 Center for Explorative Lipidomics, BioTechMed-Graz, Graz 8010, Austria \\ 5 Department of Health Sciences and Technology, ETH Zurich, Schwerzenbach 8603, Switzerland \\ 6 Department of Internal Medicine, Intensive Care Unit, Medical University of Graz, Graz 8036, Austria; \\ philipp.eller@medunigraz.at \\ * Correspondence: wolfgang.sattler@medunigraz.at
}

Received: 12 December 2019; Accepted: 6 February 2020; Published: 9 February 2020

\begin{abstract}
During inflammation, activated leukocytes release cytotoxic mediators that compromise blood-brain barrier (BBB) function. Under inflammatory conditions, myeloperoxidase (MPO) is critically involved in inflicting BBB damage. We used genetic and pharmacological approaches to investigate whether MPO induces aberrant lipid homeostasis at the BBB in a murine endotoxemia model. To corroborate findings in a human system we studied the impact of sera from sepsis and non-sepsis patients on brain endothelial cells (hCMEC/D3). In response to endotoxin, the fatty acid, ceramide, and sphingomyelin content of isolated mouse brain capillaries dropped and barrier dysfunction occurred. In mice, genetic deficiency or pharmacological inhibition of MPO abolished these alterations. Studies in metabolic cages revealed increased physical activity and less pronounced sickness behavior of $\mathrm{MPO}^{-/-}$compared to wild-type mice in response to sepsis. In hCMEC/D3 cells, exogenous tumor necrosis factor $\alpha(\mathrm{TNF} \alpha)$ potently regulated gene expression of pro-inflammatory cytokines and a set of genes involved in sphingolipid (SL) homeostasis. Notably, treatment of hCMEC/D3 cells with sera from septic patients reduced cellular ceramide concentrations and induced barrier and mitochondrial dysfunction. In summary, our in vivo and in vitro data revealed that inflammatory mediators including MPO, TNF $\alpha$ induce dysfunctional SL homeostasis in brain endothelial cells. Genetic and pharmacological inhibition of MPO attenuated endotoxin-induced alterations in SL homeostasis in vivo, highlighting the potential role of MPO as drug target to treat inflammation-induced brain dysfunction.
\end{abstract}

Keywords: blood-brain barrier; calorimetry; ceramides; cytokines; fatty acid; mitochondrial function; myeloperoxidase; sphingomyelins 


\section{Introduction}

The neurovascular unit separates most regions of the brain from the peripheral circulation to maintain the specialized central nervous system (CNS) micromilieu. Brain microvascular endothelial cells (BMVEC) form the morphological basis of the blood-brain barrier (BBB) by formation of tight junction and adherens junction complexes [1]. These junctional complexes inhibit paracellular leakage, maintain CNS homeostasis via polarized expression of transporter systems, and protect most regions of the brain from injuries. However, BBB function is compromised under inflammatory conditions and can aggravate neuronal dysfunction [2]. The lipid composition of BMVEC plays a pivotal role in barrier function by establishing a unique environment that inhibits caveolae vesicle formation to suppress transcytosis and ensure BBB integrity [3,4].

Due to structural and signaling requirements, a functional sphingolipid (SL) rheostat is indispensable for physiological vascular and BBB function [5]. De novo synthesis of SL occurs in the ER where serine palmitoyltransferase (SPT) catalyzes decarboxylation of palmitoyl-CoA and condensation with serine generating 3-ketosphinganine, which is further converted to dihydro -sphingosine, di-hydro ceramide, and finally ceramide (Cer; Figure S1). In the Golgi Cer serves as substrate for sphingomyelin (SM) synthases to generate SM species. The relative levels of these three interconvertible SL metabolites are regulated by sphingosine kinase (SPHK) 1 and -2 , which phosphorylate sphingosine to produce sphingosine-1-phosphate (S1P) ([6]; Figure S1). S1P is exported and is available as auto- or paracrine signaling molecule via five S1P receptors (S1PR1-5). Of these, S1PR1 plays a central regulatory role in BBB function [7]. Reactive oxygen (e.g., $\mathrm{H}_{2} \mathrm{O}_{2}$ ) and nitrogen (e.g., $\mathrm{ONOO}^{-}$) regulate SL metabolism [8] and signaling pathways [9]. Disruption of SL homeostasis is associated with endothelial barrier dysfunction, a hallmark of sepsis, acute lung injury, and sepsis-associated encephalopathy $[5,10,11]$. Disruptive BBB dysfunction in a murine lipopolysaccharide (LPS)-induced endotoxemia model is accompanied by alterations of the S1P rheostat in brain capillaries and dysregulation of SL homeostasis in serum and brain [11].

Reactive oxygen species (ROS) are potent regulators of vital physiological functions [12] and may improve systemic defense mechanisms [13]. However, conditions of oxidative stress, defined as an imbalance between pro- and anti-oxidants leading to disruption of redox circuitry and macromolecular damage [14], might trigger peripheral, cardiovascular, metabolic, or neurological pathologies. This discrepancy between beneficial and disease-mediating effects of ROS is probably the underlying cause for the failure of antioxidant intervention trials that were mostly ineffective or detrimental [15]. Based on this limited success, inhibition of 'ROS toxifiers' was proposed as interference strategy [16]. Myeloperoxidase (MPO), a component of the armamentarium of the innate immune system, generates ROS and reactive nitrogen species. In the presence of chloride ions, MPO, which is abundantly present in neutrophils and monocytes, converts the relatively weak two electron oxidant $\mathrm{H}_{2} \mathrm{O}_{2}$ to highly reactive hypochlorous acid ( $\mathrm{HOCl})$, a prototypic example of a 'ROS toxifier' reaction. Chronic activation of phagocytes results in elevated levels of $\mathrm{HOCl}$ that can modify a wide range of biomolecules including antioxidants, nucleotides, DNA, (lipo)proteins, and lipids. Thus, prolonged production of HOCl causes tissue injury $[17,18]$ and leads to the formation of a chlorinated lipidome with deleterious functions [18]. In addition to modification of ether-phospholipid plasmalogens [18], $\mathrm{HOCl}$ is able to modify SL [19] with a second order rate constant in the range observed for plasmalogens [20].

Here we hypothesized that inflammatory conditions activate MPO and, according to the 'ROS toxifier' concept, affect lipid and energy metabolism in brain capillaries or BMVEC due to impaired adaptation to pro-oxidant conditions. We used an LPS-induced murine endotoxemia model (recapitulating some of the sepsis-associated features observed in the mouse cecal ligation puncture model; Ref. [21]) to study the impact of MPO on SL homeostasis in brain capillaries of wild-type (wt) and $\mathrm{MPO}^{-/-}$mice or by pharmacological inhibition of MPO with 4-aminobenzoic acid hydrazide $(\mathrm{ABAH})$. In a human system, we investigated the role of inflammatory mediators (TNF $\alpha$ and serum obtained from sepsis patients) on human brain endothelial cell (hCMEC/D3) function. We investigated the role of inflammatory mediators (TNF $\alpha$ and serum from sepsis patients) in a human system based 
on the function of human brain endothelial cells (hCMEC/D3). In this 'humanized' in vitro system, we studied gene expression of interleukin-6 (IL-6) and TNF $\alpha$, and a selected set of metabolic enzymes that regulate SL turnover, barrier and mitochondrial function, SL homeostasis, and cytokine expression in vitro.

\section{Results}

Since SL homeostasis of brain capillaries is a major determinant of BBB function $[4,5]$ we first clarified the impact of sepsis-like conditions on fatty acid (FA), Cer, and SM content of murine brain microcapillaries. Endotoxemia induced by LPS injection markedly reduced palmitic (C16:0) and stearic (C18:0) acid concentrations (Figure 1A) in wt mice. There was also a tendency (though statistically not significant) for a reduction in other FA species (C16:1, C18:1, C18:2, C20:4, and C22:6). As palmitoyl-CoA is an essential substrate for the rate-limiting step in de novo SL synthesis we next determined Cer and SM content of brain capillaries by LC-ESI-MS/MS. Among the Cer species (with dihydroxy(d)18:1 backbone) Cer18:0 was significantly reduced (27\%) in response to systemic LPS-induced inflammation (Figure 1B). Among the SM-d18:1 species, SM16:0, 18:0, 22:0, and 24:1 were significantly reduced as compared to control mice (Figure 1C). We also found a decrease for other Cer and SM species, however, statistically not significant (Figure 1B,C). SL metabolism and results are summarized in Figure S1.

\section{A}

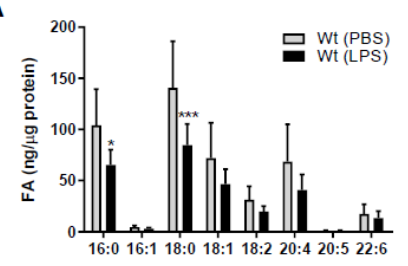

B

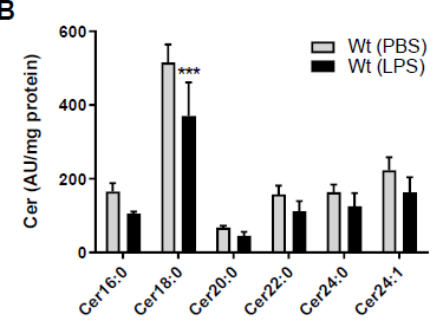

C

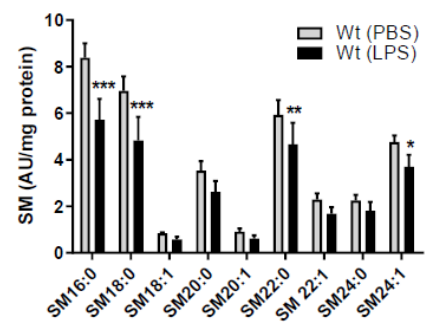

Figure 1. Peripheral lipopolysaccharide (LPS) administration decreases fatty acid (FA), ceramide (Cer), and sphingomyelin (SM) content in brain microcapillaries of wild-type (wt) mice. Wt mice received a single i.p. injection of PBS $(200 \mu \mathrm{L})$ or LPS in PBS (from Escherichia coli, 0111:B4 in PBS, $8.3 \mu \mathrm{g} / \mathrm{g}$ body weight) and were sacrificed $16 \mathrm{~h}$ after injection. (A) GC analysis of the total FA content of mouse brain microcapillaries (pooled from two brains per sample) as FA methylester derivatives. Significance was calculated by ANOVA, followed by Bonferroni correction. Data are shown as mean $(n=6-7)+$ SD. (B) Levels of Cer and (C) SM species in isolated brain microcapillaries (pooled from 3 brains per sample) were measured by LC-ESI-MS/MS. Cer and SM species are displayed on basis of their acyl chain composition. The values obtained were normalized to the internal standard and protein amount (arbitrary units (AU)/mg protein). Data are shown as mean $(n=5)+$ SD. Significance was calculated by ANOVA, followed by Bonferroni correction. ${ }^{*}, p<0.05 ;{ }^{* *}, p \leq 0.01 ;{ }^{* * *}, p \leq 0.001$. 
The fact that SL metabolism is under redox control and in turn controls redox signaling [22] prompted us to study the potential involvement of MPO in aberrant SL homeostasis in mouse brain capillaries. Therefore, we used genetic ( $\mathrm{MPO}^{-/-}$mice) and pharmacological (the MPO inhibitor ABAH in wt animals) approaches. Of note, the Cer and SM content of brain capillaries isolated either from $\mathrm{MPO}^{-/-}$mice (Figure 2A,B) or from wt mice treated with ABAH (Figure 2C,D) remained unchanged in response to LPS. To test the possibility of pharmacological interference with LPS-induced BBB breakdown, animals received injections of PBS, LPS, or LPS in combination with ABAH followed by administration of Evans Blue (EB). Peripheral LPS increased EB extravasation in this experimental setup from 0.4 to $0.7 \mu \mathrm{g} \mathrm{EB} / 100 \mathrm{mg}$ brain tissue (control vs. LPS, respectively; Figure 2E). Co-injection of PBS/ABAH was without effect on EB accumulation. Although we observed diminished EB extravasation in LPS/ABAH injected mice as compared to LPS alone (0.56 vs. $0.7 \mu \mathrm{g} \mathrm{EB/100} \mathrm{mg} \mathrm{brain,} \mathrm{LPS/ABAH} \mathrm{vs.}$ LPS), however, this difference did not reach statistical significance (Figure 2E).

A

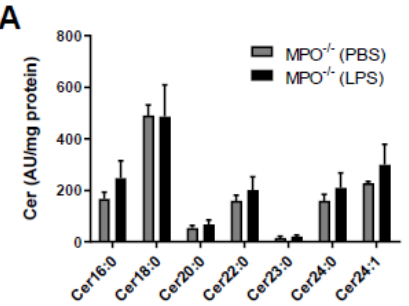

C

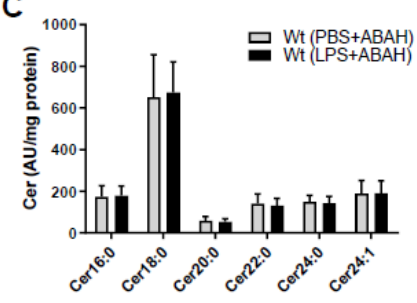

E



B



D

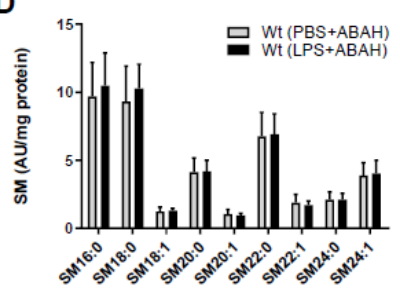

Figure 2. Myeloperoxidase $(\mathrm{MPO})^{-/-}$or pharmacological MPO inhibition by $\mathrm{ABAH}$ prevents aberrant brain capillary sphingolipid homeostasis in response to peripheral LPS. (A,B) Cer and SM content of microcapillaries (pooled from three brains per sample) of PBS or LPS (8.3 $\mu \mathrm{g} / \mathrm{g}$ body weight) injected $\mathrm{MPO}^{-/-}$mice were analyzed by LC-ESI-MS/MS. The values were normalized to the internal standard and protein amount. Data are shown as mean $(n=4)+$ SD. $(\mathbf{C}, \mathbf{D})$ Wt mice were injected with PBS or LPS $(8.3 \mu \mathrm{g} / \mathrm{g}$ body weight $) \pm$ ABAH $(40 \mu \mathrm{g} / \mathrm{g}$ body weight; injected $2 \mathrm{~h}$ before and $5 \mathrm{~h}$ after PBS or LPS injection). Cer and SM content of microcapillaries (pooled from three brains per sample) was analyzed by LC-ESI-MS/MS. Data are shown as mean $(n=7)+$ SD. (E) Wt mice received a single i.p. injection of PBS or LPS ( $8.3 \mu \mathrm{g} / \mathrm{g}$ body weight $) \pm \mathrm{ABAH}(40 \mu \mathrm{g} / \mathrm{g}$ body weight; injected twice: $2 \mathrm{~h}$ before and $5 \mathrm{~h}$ after PBS or LPS injection) and Evans Blue (3\% in PBS; $4 \mu \mathrm{L} / \mathrm{g}$ body weight). Twelve hours post treatment, animals were anaesthetized with pentobarbital $(150 \mathrm{mg} / \mathrm{kg}$ body weight) and transcardially perfused with $25 \mathrm{~mL}$ PBS. Brains were removed, frozen in liquid nitrogen, and homogenized. Evans Blue was quantitated spectrophotometrically using an external Evans Blue calibration curve. Results represent mean values (PBS: $n=14$, PBS+LPS: $n=13$, PBS+ABAH: $n=13$, PBS+ABAH+LPS: $n=6$ ) \pm SD. Significance was calculated by ANOVA, followed by Bonferroni correction. ${ }^{*}, p \leq 0.05 ;{ }^{* * *}, p \leq 0.001$. 
Activation of the immune system during systemic inflammation can induce sickness behavior [23] and forced expression of human MPO in a murine Parkinson's Disease model exacerbates motor impairment [24]. HOCl scavengers were suggested to modulate sickness/motor behavior in a murine model of inflammation [25]. To study this aspect more directly we monitored the effects of low-grade inflammation on metabolic, physiological, and behavioral activities of wt and $\mathrm{MPO}^{-/-}$animals. Short ( $24 \mathrm{~h}$ post first LPS injection)- and long-term (averaged over the entire 5-days treatment period) readouts of these experiments are displayed in Figure 3 and Figure S2, respectively. The mean respiratory exchange ratio (RER) measured by indirect calorimetry was calculated as the ratio of the amounts of $\mathrm{CO}_{2}$ produced and $\mathrm{O}_{2}$ consumed. Total RER (Figure 3A, blue box) and mean RER (Figure 3B) were markedly higher in $\mathrm{MPO}^{-/-}$animals, indicating preferential metabolism of carbohydrates over lipid oxidation. In fact, carbohydrate oxidation was 5.7-fold (light cycle) higher in $\mathrm{MPO}^{-/-}$mice (Figure 3C), whereas lipid oxidation was lower (Figure 3D). Food intake and water consumption during the light cycle was significantly higher in $\mathrm{MPO}^{-/-}$mice (Figure 3E,F). Locomotor activity was markedly increased in $\mathrm{MPO}^{-/}$mice (Figure 3G), while energy expenditure was unaltered (Figure 3H). The corresponding data averaged over the entire 5-day treatment period are shown in Figure S2. Our findings indicate that $\mathrm{MPO}^{-/-}$mice are less affected by LPS-induced sickness behavior as compared to wt animals.

To elucidate whether the loss or inhibition of MPO affects circulating concentrations of cytokines known to impact sickness behavior and BBB function [23] we quantitated IL-1 $\beta$, IL-6, and TNF $\alpha$ levels by ELISA. In wt animals, peripheral LPS increased the levels of all three cytokines (Figure 4A-C). Surprisingly, ABAH resulted in already higher baseline concentrations of IL- 6 and TNF $\alpha$, which were not further increased by LPS (Figure 4A-C). Wt, Wild type.

One of the signaling pathways known to contribute to sepsis-induced BBB dysfunction is triggered by binding of systemic TNF $\alpha$ to the neurovasculature leading to induction of cyto-/chemokine synthesis that causes BBB disruption [26,27]. In line, treatment of human hCMEC/D3 cells with recombinant $\mathrm{TNF} \alpha(\mathrm{rTNF})$ upregulated IL-6 mRNA in a time- and concentration-dependent manner (Figure 5A). Upregulation of endogenous TNF $\alpha$ with 1000-fold mRNA induction was even more pronounced after $1 \mathrm{~h}$ in response to $10 \mathrm{ng} / \mathrm{mL} \mathrm{rTNF} \alpha$ (Figure $5 \mathrm{~B}$ ). Thus, these experiments support the notion that extracellular rTNF $\alpha$ can induce a vicious cycle of endogenous cytokine synthesis in BMVEC. qPCR analyses revealed that serine palmitoyltransferase 3 (SPTLC3), ceramide synthase 1 (CERS1), alkaline ceramidase 2 (ACER2), and acid ceramidase (ASAH1) were downregulated, while sphingosine kinase 1 (SPHK1) gene expression was upregulated in response to the highest TNF $\alpha$ concentration (Figure 5C).

To gain insight into the effects of septic conditions on hCMEC/D3 cells we initiated a small observational study utilizing serum samples from septic and non-septic patients admitted to the intensive care unit (ICU, sepsis was diagnosed as outlined in Materials and Methods). Serum samples of sepsis patients (as compared to non-septic patients) contained higher neutrophil counts $\left(13.3 \times 10^{9}\right.$ vs. $6.5 \times 10^{9}$ cells $/ 1$; Figure $6 \mathrm{~A}$, left panel) and higher concentrations of MPO (13.1 vs. $8.8 \mathrm{ng}$ protein $/ \mathrm{mL}$; Figure 6A, right panel), IL-6 (188 vs. 23 pg/mL; Figure 6B), and TNF $\alpha$ ( 348 vs. 63 pg/mL). IL-1 $\beta$ concentrations were below the limit of detection in five samples in both groups (resulting in a median of zero, Figure 6B). 
A

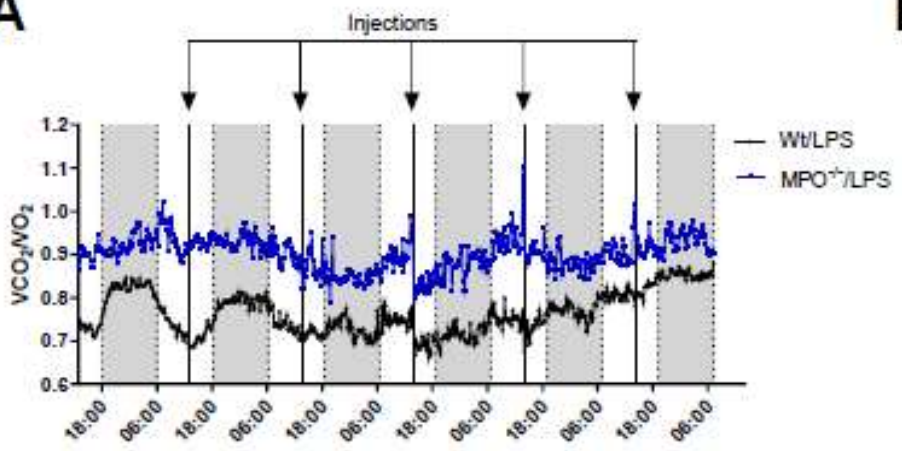

B

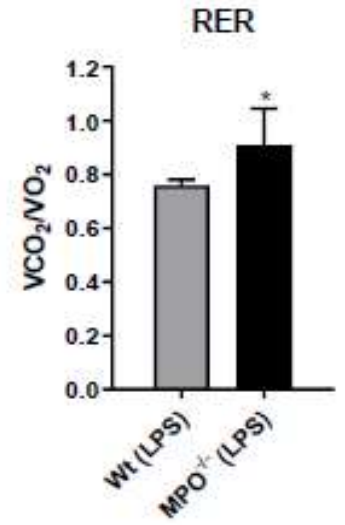

C

\section{Carbon oxidation}

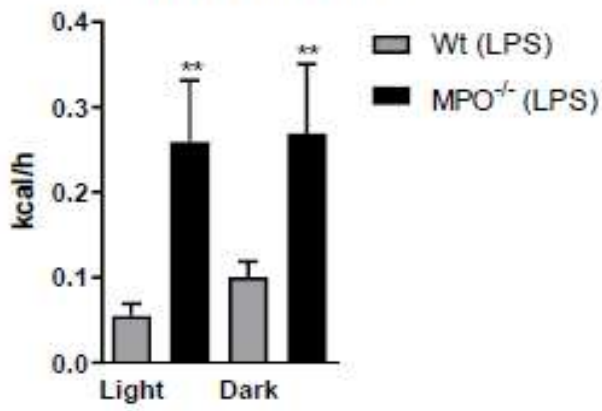

E

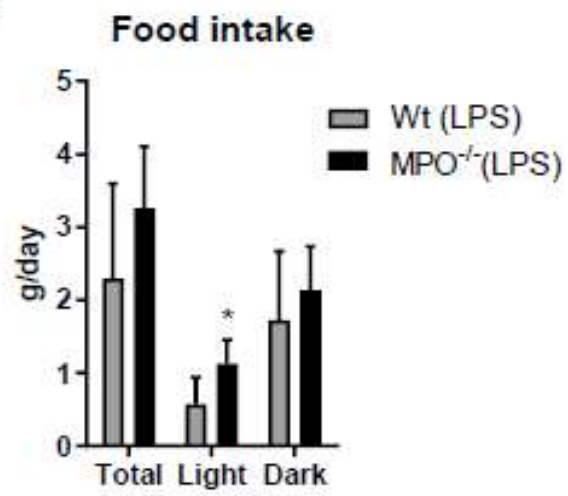

G

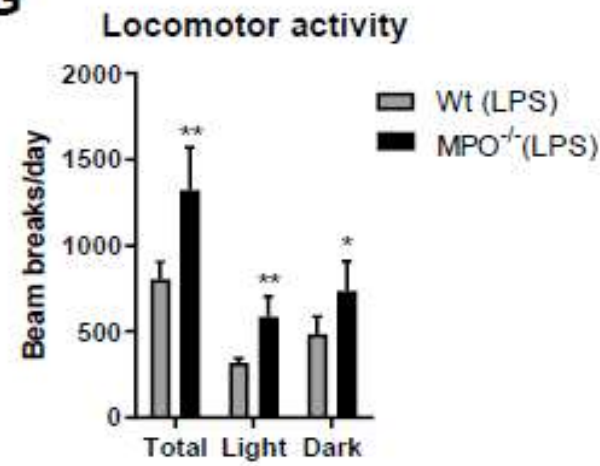

D Lipid oxidation



$\mathbf{F}$ Water consumption

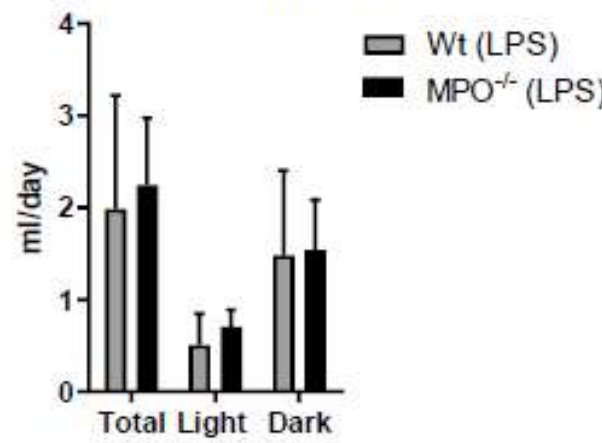

$\mathrm{H}$

Energy expenditure

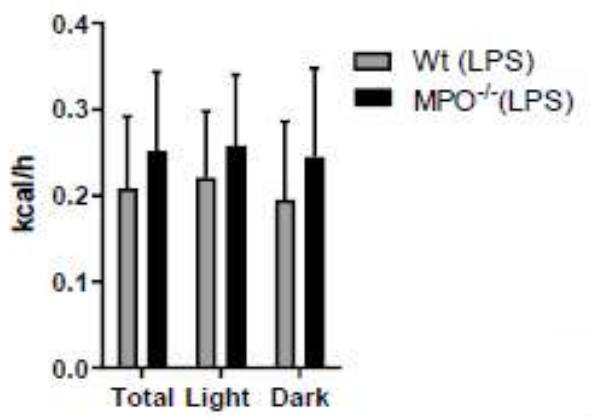

Figure 3. Short term metabolic cage readouts $24 \mathrm{~h}$ after first LPS injection. Wt and $\mathrm{MPO}^{-/-}$mice were housed at room temperature in metabolic cages with free access to chow diet and water. Mice were injected daily with LPS (i.p. $0.83 \mu \mathrm{g} / \mathrm{g}$ body weight) for $5 \mathrm{~d}$. (A) Total (blue box represents the $24 \mathrm{~h}$ period after the first LPS injection) and (B) mean respiratory exchange ratio (RER), (C) carbohydrate oxidation, (D) lipid oxidation, (E) daily food intake, (F) water consumption, (G) locomotor activity, and $(\mathbf{H})$ energy expenditure were measured for $24 \mathrm{~h}$ after the first LPS injection. Data represent means $(n=6)+$ SD. Significance was calculated by student's unpaired $t$-test, followed by Welch's correction in case of unequal variances. ${ }^{*}, p \leq 0.05 ;{ }^{*}, p<0.01$. 


\section{A}

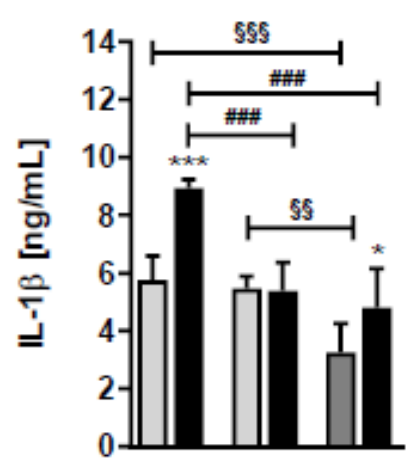

B



C

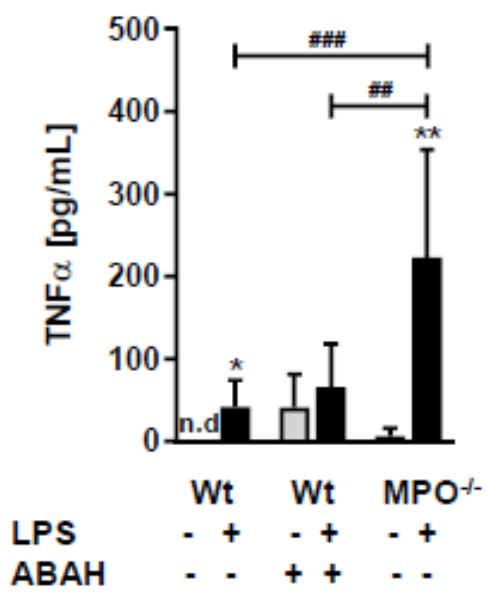

Figure 4. LPS differently affects plasma cytokine levels in wt, $\mathrm{ABAH}$-treated, and $\mathrm{MPO}^{-/-}$mice. Wt and $\mathrm{MPO}^{-/-}$mice received a single i.p. injection of PBS (control) or LPS $(8.3 \mu \mathrm{g} / \mathrm{g}$ body weight $) \pm \mathrm{ABAH}$ ( $40 \mu \mathrm{g} / \mathrm{g}$ body weight; injected twice: $2 \mathrm{~h}$ before and $5 \mathrm{~h}$ after PBS or LPS injection). Twelve hours post treatment blood was collected by submandibular puncture and assayed for (A) IL-1 $\beta$, (B) IL- 6 , and (C) $\mathrm{TNF} \alpha$ concentrations by ELISA. Data are shown as mean $(n=7)+\mathrm{SD}$. Significance was calculated by ANOVA, followed by Bonferroni correction. ${ }^{*}, p \leq 0.05$; ${ }^{* *}, \# \#, \$ \S, p<0.01$; \#\#, $\$ \S \S, p<0.001$; n.d.: not detected. * wt, PBS vs. LPS; \#\#, \#\#\# wt vs. $\mathrm{MPO}^{-/-}$; $\$ \S, \S \S \S$ wt/PBS vs. wt/PBS/ABAH or $\mathrm{MPO}^{-/-} / \mathrm{PBS}$. 
A

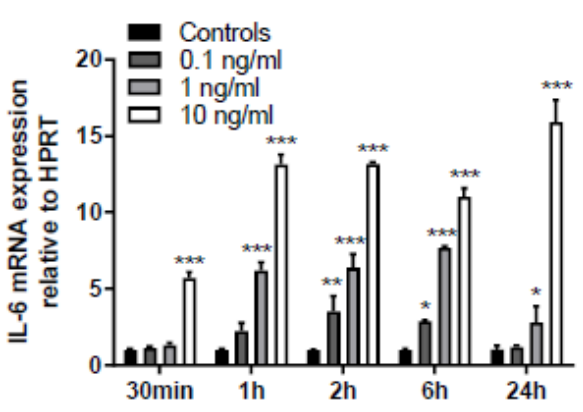

B

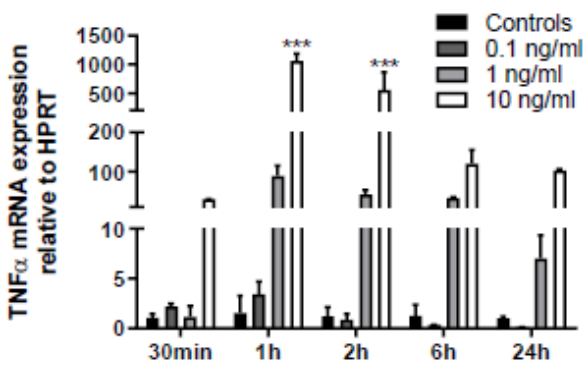

\section{C}

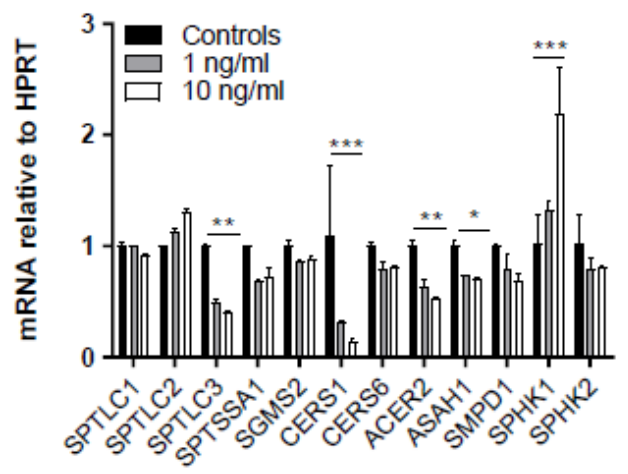

Figure 5. Exogenous TNF $\alpha$ increases in cytokine synthesis and regulates expression of genes involved in sphingolipid metabolism. Serum-starved human brain endothelial (hCMEC/D3) cells were treated with the indicated $\mathrm{rTNF} \alpha$ concentrations (0.1-10 ng) for the indicated times and gene expression of (A) IL-6 and (B) TNF $\alpha$ was evaluated by qPCR analysis. Hypoxanthine-guanine phosphoribosyltransferase (HPRT) was used as housekeeping gene. Data are shown as mean $(n=4)+\mathrm{SD}$. (C) hCMEC/D3 cells were incubated with 1 or $10 \mathrm{ng} / \mathrm{mL} \mathrm{TNF} \alpha$ for $2 \mathrm{~h}$ and expression of serine palmitoyltransferase 1-3 (SPTLC1-3), serine palmitoyltransferase small subunit A (SPTSSA1), sphingomyelin synthase 2 (SGMS2), ceramide synthase 1 and 6 (CerS1 and CerS6), alkaline ceramidase 2 (ACER2), acid ceramidase (ASAH1), sphingomyelinase 1 (SMPD1), and sphingosine kinase 1 and 2 (SPHK1 and 2) was evaluated by qPCR analysis. Data are shown as mean $(n=3)+\mathrm{SD}$. Expression was calculated using the $2^{-\mathrm{ddCt}}$ method. *,$p \leq 0.05 ;{ }^{* *}, p<0.01 ;{ }^{* * *}, p<0.001$. Significance was calculated by ANOVA, followed by Bonferroni correction. 
A

C
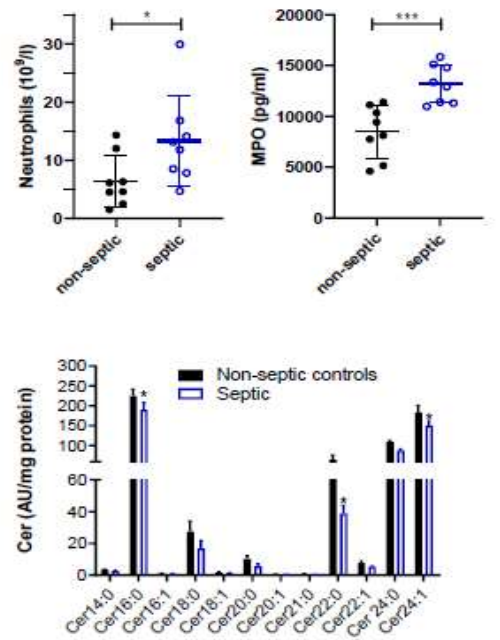

E

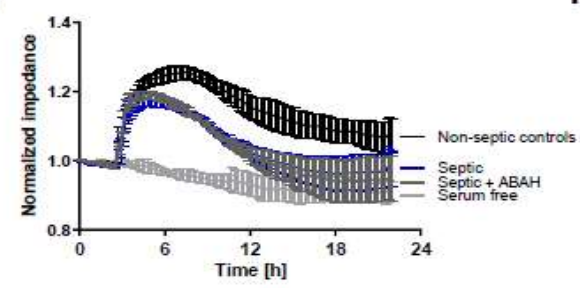

G

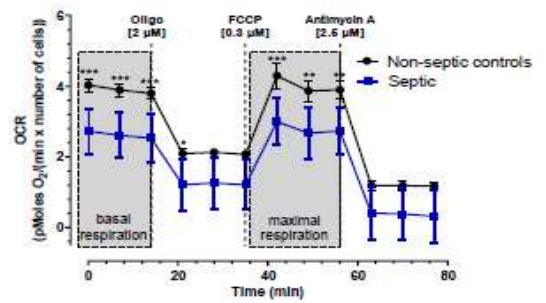

B

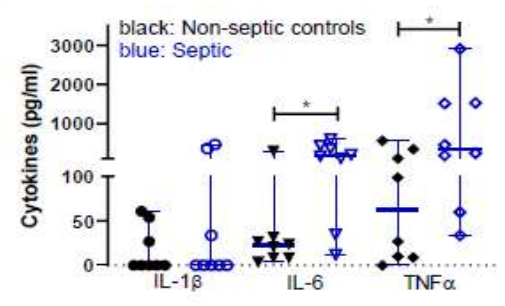

D

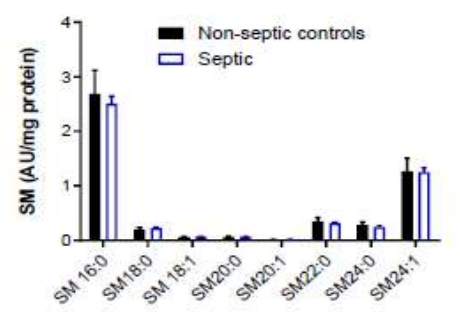

$\mathbf{F}$

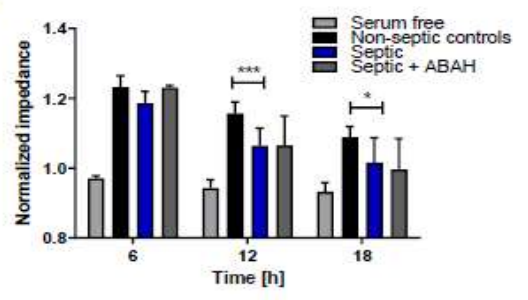

Figure 6. Samples from sepsis patients contain higher neutrophil counts and higher concentrations of MPO, IL-6, and TNF $\alpha$, and disrupt Cer homeostasis, barrier function, and mitochondrial respiration of hCMEC/D3 cells. (A) Blood or serum samples obtained from non-septic and septic patients were assayed for neutrophil counts and MPO. Results are presented as mean \pm SD ( $n=8$ per group). (B) Cytokine concentrations in serum samples obtained from non-septic and septic patients. Results are shown as median $\pm 95 \% \mathrm{CI}(n=8$ per group). Significance was calculated by Mann-Whitney test. (C,D) Serum-starved hCMEC/D3 cells were treated with serum from non-septic or septic patients for $12 \mathrm{~h}$. Cer and SM species were measured by LC-ESI-MS/MS. The values obtained were normalized to the internal standard and protein content (arbitrary units (AU)/mg protein). Results are shown as mean $(n=4)+$ SD. (E) hCMEC/D3 cells were plated on collagen-coated gold microelectrodes, cultured to confluence, and serum-starved overnight. Impedance of cell monolayers was continuously monitored at $4 \mathrm{kHz}$ ( $n=2$, in duplicate). After stabilization, serum from non-septic or septic patients was added to the cells. Serum free media served as controls. (F) Statistical evaluation of normalized impedance values of hCMEC/D3 cells cultured in the presence of serum from non-septic or septic $( \pm \mathrm{ABAH} ; 100 \mu \mathrm{M})$ patients ( $n=8$ per group). Results are shown as mean $+\mathrm{SD}$. (G) hCMEC/D3 cells $(50.000$ cells/well) were cultured with sera $(20 \%)$ from non-septic $(n=4)$ or septic patients $(n=4)$ and subsequently oxygen consumption rate (OCR) was analyzed in the presence of $25 \mathrm{mM}$ glucose and $2 \mathrm{mM}$ L-glutamine. Cells were treated with $2 \mu \mathrm{M}$ oligomycin (oligo), $0.3 \mu \mathrm{M}$ carbonyl cyanide-4-(trifluoromethoxy)phenylhydrazone (FCCP), and $2.5 \mu \mathrm{M}$ antimycin A. Values were normalized to the protein content. Data are presented as mean values \pm SD of sextuplicate determinations. ${ }^{*}, p \leq 0.05 ; * *, p<0.01 ; * * *, p<0.001$. Significance was calculated by ANOVA, followed by Bonferroni correction. 
Since proinflammatory cytokines, in particular TNF $\alpha$, are potent modulators of SL homeostasis we analyzed the Cer and SM content of hCMEC/D3 cells incubated in the presence of non-septic and septic serum samples. In accordance with our in vivo findings in the murine endotoxemia model, LC-MS/MS analyses revealed significantly reduced Cer16:0, Cer22:0, and Cer24:1 content in hCMEC/D3 cells cultured in the presence of sera from sepsis patients (Figure 6C) while SM species remained unaffected when compared to non-septic samples (Figure 6D). Real-time monitoring of hCMEC/D3 barrier function demonstrated that cells cultured in the presence of serum obtained from sepsis patients developed significantly lower transendothelial impedance as compared to non-septic serum (Figure 6E,F). No effects were observed at $64 \mathrm{kHz}$, being indicative of intact cell monolayers (data not shown). However, despite higher MPO content in serum of sepsis patients, the addition of ABAH resulted only in a marginal increase of impedance values at the $6 \mathrm{~h}$ time point (Figure $6 \mathrm{~F}$ ) and was without effect at the 12 and $24 \mathrm{~h}$ time points. Inflammatory conditions can impair BBB integrity through induction of a mitochondrial crisis [28]. In line, measuring oxygen consumption rate (OCR) revealed that septic serum samples significantly attenuated basal and maximal respiration of hCMEC/D3 cells (Figure 6G), supporting the concept that inflammatory mediators interfere with BMVEC function.

\section{Discussion}

The present study provides evidence that endotoxemia affects FA, Cer, and SM homeostasis in isolated mouse brain microvessels (Figure 1). Pharmacological or genetic interference with MPO activity showed benefits by maintaining SL homeostasis in response to peripheral LPS. This is reminiscent of what was found in other CNS-related disease models: Inhibition of MPO reduces brain damage in a murine stroke model [29], reduces oxidative stress-induced neuronal damage [30], ameliorates experimental autoimmune encephalomyelitis (EAE) disease severity [31], improves inflammatory parameters in 6-hydroxydopamine induced Parkinsonism [32], and increases neurogenesis after ischemic stroke in mice [33]. Antagonism of MPO activity by ABAH as well as genetic deletion of MPO resulted in improved the outcome in the transient middle cerebral artery occlusion mouse model [34]. $\mathrm{MPO}^{-/-}$mice show better functional recovery after spinal cord injury [35]. Moreover, LPS-induced BBB dysfunction and barrier dysfunction of primary BMVEC was rescued by ABAH treatment [36]. During the present study ABAH slightly diminished LPS-induced EB accumulation in brain (Figure 2E), this effect was, however, not statistically significant. This is probably due to some limitations related to our experimental setup since we did not quantitate circulating dye concentrations. In patients, elevated circulating MPO levels were associated with small vessel-related stroke risk [37]. The Ford group has previously reported that 2-chloro FA formed via HOCl-mediated attack of plasmalogens contribute to pulmonary endothelial injury and have prognostic utility in sepsis-associated acute respiratory distress syndrome [38]. Therefore, the pharmacological benefit for MPO in preclinical settings of neurological disease models including inflammation-induced BBB dysfunction is following the 'inhibit ROS toxifiers' concept.

The production of reactive species and proinflammatory cytokines by neutrophils at sites distant from the initial infection suggested that this cell type contributes to organ damage in sepsis [39]. Indeed, Carr and colleagues showed that circulating MPO is elevated in patients with septic shock and associated with organ failure and mortality in critically ill patients despite comparable neutrophil counts in septic shock and non-septic patients [40]. On the other hand, in human sepsis patients diminished MPO expression was identified as the best predictor to identify a subgroup of patients at high risk of death [41]. Reber and colleagues reported the development of a mouse model that enables specific diphteria toxin-induced neutrophil ablation [42]. These authors demonstrated that neutrophils protect the host from LPS-induced lethal inflammation and showed that MPO plays a major role in this protective pathway by adoptive transfer experiments. In contrast to data obtained during the present study where ABAH ameliorated aberrant SL homeostasis in vivo Reber and colleagues reported ABAH-induced mortality in response to LPS-induced inflammation [42]. Currently, the 
reason(s) for these contradictory findings are still unclear could be, however, due to different LPS and ABAH concentrations used during the present study.

Multifactorial mechanisms that drive aberrant SL homeostasis in brain microcapillaries under inflammatory/septic conditions can be envisaged. Endothelial cells express the enzymatic machinery necessary for de novo FA synthesis. LPS-induced endotoxemia suppresses FA synthase mRNA levels and de novo FA synthesis in vivo [43,44]. We observed reduced total FA content in brain capillaries isolated from endotoxin-treated mice (Figure 1A). This is most probably a reflection of decreased lipolysis and a subsequent decrease of FA import into microcapillaries due to decreased lipoprotein lipase activity and expression of the FA transporter CD36 under inflammatory conditions [45]. Substrate limitation due to reduced availability of palmitic acid for the first and rate limiting step of SL synthesis is a reasonable explanation for decreased Cer and SM concentrations in brain capillaries of LPS-treated wt mice (Figure 1B,C). A similar decrease was observed for several lyso-phosphatidylcholine species in human LPS-treated BMVEC in an organ-on-chip model [46]. SL homeostasis is under control of inflammatory mediators that affect the activity of several enzymes within this metabolic pathway. TNF $\alpha$ stimulates SL metabolic enzymes including sphingomyelinases, ceramidases, and SPHK1 [6,47]. Vutukuri and colleagues demonstrated that endotoxemia increases the Cer concentrations in mouse serum (but not in brain or brain capillaries) while S1P concentrations in serum, whole brain and in brain capillaries are decreased [11]. In brain capillaries, these observations were ascribed to transcriptional and translational upregulation of S1P phosphatase as well as lipid phosphate phosphatase 1, and to downregulation of SPHK2 [11]. In contrast, we observed lower concentrations of Cer and SM species in brain capillaries which might be due to higher LPS concentrations used in the present study (8.3 vs. $4 \mu \mathrm{g} / \mathrm{g}$ body weight).

The 'inhibit ROS toxifier' concept holds promise to preserve SL homeostasis in brain capillaries for several reasons: i) sphingomyelinases and ceramidases are regulated by stress signaling [22] that might be attenuated in the absence of MPO activity, ii) sphingomyelinases are activated by ROS and reactive nitrogen species, and iii) $\mathrm{HOCl}$ generated by the $\mathrm{MPO}-\mathrm{H}_{2} \mathrm{O}_{2}-\mathrm{Cl}^{-}$system oxidatively modifies lipids including plasmalogens [38,48-50] and SL [19,20,51].

Higher food intake and locomotor activity of LPS-treated $\mathrm{MPO}^{-/-}$animals compared to wt mice (Figure 3) indicate less pronounced sickness behavior in mice lacking MPO. Although this is surprising due to the higher LPS-induced TNF $\alpha$ concentrations observed in $\mathrm{MPO}^{-/-}$mice (Figure 4), which might be a result of increased TNF $\alpha$ release by activated $\mathrm{MPO}^{-/-}$neutrophils [52]. On the other hand, reduced sickness behavior might be due to defective $\mathrm{HOCl}$ production and the absence of MPO-derived chlorinated lipids. Whether or not these lipids could induce comparable behavioral deficits as reported for chlorinated dopamine [53] is currently unknown. However, intrastriatal administration of chlorodopamine resulted in loss of dopaminergic neurons and decreased locomotor activity in mice in a manner similar as observed for the Parkinsonian toxin $\mathrm{MPP}^{+}$[53]. Selective serotonin reuptake inhibitors ameliorated LPS-induced sickness behavior in wt mice [25], a potential result of $\mathrm{HOCl}$ scavenging by serotonin which is a high-affinity substrate for MPO-mediated oxidation [25]. The fact that brains of transgenic APP/PS1 mice contain far higher $\mathrm{HOCl}$ concentrations as compared to wt littermates makes it conceivable that MPO derived oxidants have the potential to contribute to induce behavioral and cognitive deficits [54].

$\mathrm{TNF} \alpha$ plays a pivotal role in sepsis-mediated organ dysfunction and induces cerebral edema via TNF receptor 1-mediated pathways in a mouse model [55]. In line, our results demonstrate that exogenously supplied TNF $\alpha$ increases mRNA levels of TNF $\alpha$ and IL-6 in hCMEC/D3 cells (Figure 5A,B), indicating a potentially vicious cycle in the neurovasculature as both cytokines are able to induce BBB dysfunction in vitro [56] and in vivo [57]. TNF $\alpha$ also affects expression of key genes centrally involved in SL homeostasis (Figure 5C). Downregulation of SPTLC3 indicates decreased synthetic flux through 3-ketodihydrosphingosine, the first step in SL biosynthesis ([6]; Figure S1). Reduced mRNA expression of CerS1, which is responsible for the synthesis of C18 Cer and expressed in the mouse brain and spinal cord [58] might explain the lower concentration of these species in brain capillaries 
isolated from LPS-treated mice. Of note, CerS6, catalyzing Cer16:0 synthesis [58] was decreased in hCMEC/D3 cells treated with TNF $\alpha$. Accordingly we observed reduced Cer16:0 concentrations in rTNF $\alpha$-exposed hCMEC/D3 cells and in brain capillaries of LPS-treated wt mice. SL composition in murine brain capillaries and human hCMEC/D3 cells was substantially different (Figure 1B,C and Figure 6C,D). In capillaries Cer18:0 and SM16:0/SM18:0 represent the most abundant species while in hCMECD3 cells Cer16:0 and SM16:0 are the main representatives. These findings might be a result of species-related differences as reported for molecular Cer composition of human prefrontal cortex and murine forebrain [59]. Brain capillary SPHK1 is upregulated in LPS-treated mice [11]. This adaptive mechanism plays an important role during TNF $\alpha$-mediated NF-kB activation results in SPHK1-dependent S1P formation, S1P binding to TRAF2, and subsequent induction of cytoprotective pathways [60].

Cytokines, matrix metalloproteinases, and/or reactive species increase BBB permeability during the inflammatory response [61]. In septic samples, we observed higher neutrophil counts, as well as higher MPO, IL-6, and TNF $\alpha$ concentrations (Figure 6A,B). In terms of MPO content these findings are in line with a recent report [40], however, in contrast to the present study the authors reported comparable neutrophil numbers in sepsis and non-sepsis samples. In response to septic serum supplementation barrier function was reduced but not recovered in the presence of $\mathrm{ABAH}$ (Figure $6 \mathrm{E}, \mathrm{F}$ ). This might be a result of the higher cytokine content in septic serum or insufficient $\mathrm{H}_{2} \mathrm{O}_{2}$ generation by hCMEC/D3 cells needed as co-substrate for $\mathrm{HOCl}$ generation via MPO. Seahorse measurements revealed reduced basal and maximal respiration of cells cultured in the presence of sepsis serum (Figure 6G). Mitochondrial dysfunction is a key contributor to LPS-induced exacerbation of BBB dysfunction and stroke outcome in a murine model [28]. Since mitochondrial function depends on SL homeostasis [62], the drop in OCR might result from decreased Cer content (Figure 6C) in hCMEC/D3 cells cultured in the presence of plasma from sepsis patients. It is plausible that decreased CERS1 mRNA expression (Figure 6C) and a concomitant downregulation of Hsp27/CERS1-dependent pathways could account for decreased mitochondrial Cer levels. If occurring (not addressed experimentally in this study), a reduction in mitochondrial Cer concentrations likely induces structural and functional changes in mitochondria as observed in a model of Charcot-Marie-Tooth disease, the most commonly inherited neurological disorder [63].

We conclude that MPO and inflammatory mediators affect SL homeostasis in murine brain microcapillaries in vivo and human brain endothelial cells in vitro. Pharmacological inhibition of the ROS toxifier MPO holds promise to interfere with aberrant SL homeostasis in brain capillaries and to partially rescue BBB dysfunction under septic conditions in vivo.

\section{Materials and Methods}

\subsection{Materials}

Cell culture supplies were from Thermo Fisher Scientific (Waltham, MA, USA) and Sigma-Aldrich (St. Louis, MO, USA). Plastic ware for cell culture was obtained from Costar (Vienna, Austria) or VWR (Vienna, Austria). Seahorse XF96 polystyrene D3 cell culture microplates were from Seahorse Bioscience $^{\circledR}$ (Agilent; Santa Clara, CA, USA). Human ELISA kits were from ImmunoTools (Friesoythe, Germany). Mouse ELISA kits were from Peprotech (Rocky Hill, NJ, USA). LPS from E. coli (O111:B4), pentobarbital sodium salt, ABAH, and Evans Blue (EB) were from Sigma-Aldrich (St. Louis, MO, USA). Human recombinant TNF $\alpha(\mathrm{rTNF} \alpha)$ was from Thermo Fisher (Vienna, Austria). Electrical cell-substrate impedance sensing (ECIS) electrode arrays $(8 \mathrm{~W} 10 \mathrm{E}+)$ were from Ibidi (Martinsried, Germany). Sera from non-sepsis or sepsis patients were obtained from the Department of Internal Medicine, ICU, Medical University of Graz. Kits that were used for quantitative real-time PCR (qPCR) analysis were from QIAGEN (Hilden, Germany) or Applied Biosystems (Foster City, CA, USA). Primers were ordered from QIAGEN. 


\subsection{Animals}

$\mathrm{MPO}^{-/-}$mice (B6.129X1-Mpo ${ }^{\mathrm{tm} 1 \mathrm{Lus} / \mathrm{J})}$ were obtained from the Jackson Laboratory (Bar Harbor, ME, USA). Genotyping was performed from ear tags using standard PCR protocols. C57BL/6 mice were obtained from the Department of Laboratory Animal Science (Himberg, Austria). All animals were kept on a $12 \mathrm{~h} \mathrm{light/dark} \mathrm{cycle} \mathrm{with} \mathrm{free} \mathrm{access} \mathrm{to} \mathrm{food} \mathrm{and} \mathrm{water.} \mathrm{Animal} \mathrm{experiments} \mathrm{were}$ approved by the Austrian Federal Ministry of Science, Research, and Economy, Division of Genetic Engineering and Animal Experiments (BMBWF-66.010/0067-V/3b/2018). The Austrian Federal Ministry of Education, Science and Research, Division of Genetic Engineering and Animal Experiments approved the animal experiments (06.07.2018; BMWF-66.010/0067-V/3b/2018). The Ethics Committee of the Medical University of Graz approved this observational clinical study (Dec 27th 2018; \#30-258 ex 17/18), and all patients provided written informed consent.

\subsection{Evans Blue (EB) Extravasation}

Wt and $\mathrm{MPO}^{-/-}$mice (8-12 weeks, 20-30 g) were injected i.p. with PBS (pH 7.4) or LPS (8.3 $\mu \mathrm{g}$ in $\mathrm{PBS} / \mathrm{g}$ body weight $) \pm \mathrm{MPO}$ inhibitor ABAH $(40 \mu \mathrm{g} / \mathrm{g}$ body weight $)$. Changes in vascular permeability during systemic inflammation were determined by i.p. injection of $3 \%$ EB in PBS $(4 \mu \mathrm{L} / \mathrm{g}$ body weight) at treatment start. After $12 \mathrm{~h}$ mice were anesthetized with $150 \mathrm{mg} / \mathrm{kg}$ pentobarbital and transcardially perfused with PBS. Subsequently, brains were removed, weighed, and homogenized in dimethylformamide (DMF). After extraction for $1 \mathrm{~h}$ on a rotating wheel, samples were centrifuged at $21,500 \times g$ for $15 \mathrm{~min}$ and EB was quantified spectrophotometrically at $620 \mathrm{~nm}$ using an external calibration curve. Due to known limitations of the EB method (e.g., spectral shifts of EB absorption in the presence of proteins, leakage of free dye, or toxicity when injected at very high concentrations) we used the dye at average concentration, extracted the dye with DMF, always prepared external EB standards immediately prior to measurements, and do not claim that EB accumulation equals albumin extravasation into the brain. Time points $<24 \mathrm{~h}$ post LPS $(8.3 \mu \mathrm{g} / \mathrm{g}$ body weight $)$ were chosen to minimize animal suffering according to the $3 \mathrm{R}$ principles (in our experience animal survival at $16 \mathrm{~h}$ is $100 \%$ while mortality significantly increases at time points $>18 \mathrm{~h}$ ).

\subsection{Brain Capillary Isolation}

Mouse brain microcapillaries were isolated by density-gradient centrifugation, as described previously [64]. Briefly, a mouse brain was immersed in ice-cold PBS and the cerebellum, meninges, brainstem, and large blood vessels were removed. The cortex was homogenized in ice-cold DMEM (Gibco) containing 10\% $(v / v)$ fetal calf serum (FCS) in a Dounce homogenizer. The homogenate was centrifuged at $500 \times g$ for $10 \mathrm{~min}$ at $4{ }^{\circ} \mathrm{C}$ and the supernatant was discarded. The pellet was homogenized in DMEM containing 10\% FCS and passed through a $100 \mu \mathrm{m}$ mesh nylon filter. The filtrate was passed again through a $40 \mu \mathrm{m}$ mesh nylon filter. The fraction retained on the $40 \mu \mathrm{m}$ filter was collected, suspended in ice-cold DMEM containing 10\% FCS and centrifuged at $12,000 \times g$ for $45 \mathrm{~min}$ at $4{ }^{\circ} \mathrm{C}$. The supernatant was discarded and the pellet containing the microcapillaries was resuspended in $500 \mu \mathrm{L}$ erythrocyte lysis buffer. After $2 \mathrm{~min}, 500 \mu \mathrm{L}$ PBS were added to stop the reaction and the microcapillaries were again spun down at $12,000 \times g$ for $20 \mathrm{~min}$ at $4{ }^{\circ} \mathrm{C}$. The supernatant was discarded and the pellet stored at $-80^{\circ} \mathrm{C}$.

\subsection{Indirect Calorimetry (Energy Expenditure, Locomotor Activity)}

$\mathrm{MPO}^{-/-}$and wt mice were individually housed in PhenoMaster cages (TSE Systems, Bad Homburg, Germany) for measuring energy intake- and expenditure-related data over 5 days and injected with LPS ( $0.83 \mu \mathrm{g}$ in PBS/g body weight) every $24 \mathrm{~h}$. This chronic low-dose endotoxemia model was chosen to be able to monitor animal behavior over an extended period of time (in the acute high-dose LPS model used in the experimental paradigm described above animal suffering increases at time points $>18 \mathrm{~h}$ post LPS application). The cage system included photobeam-based activity monitoring that 
records ambulatory movements. An indirect gas calorimetry system simultaneously measured oxygen consumption $\left(\mathrm{VO}_{2}\right)$, carbon dioxide production $\left(\mathrm{VCO}_{2}\right)$, respiratory exchange ratio (RER), and food and water intake.

\subsection{Human Blood Samples}

Patients were recruited from the ICU of the Department of Internal Medicine at the Medical University of Graz. The Ethics Committee of the Medical University of Graz approved the prospective study protocol (\#30-258 ex17/18), and all patients provided a written informed consent. Critically-ill patients with sepsis were defined by sepsis- 3 criteria with a suspected infection and a rise in sequential organ failure assessment (SOFA) score $\geq 2$ [65]. Comfort terminal care, pregnancy, and age $>100$ years were exclusion criteria. Critically ill patients without infection served as controls. Immediately after admission to the ICU blood samples $(4 \mathrm{~mL})$ were collected and serum was isolated and stored at $-80^{\circ} \mathrm{C}$. Neutrophils were immediately counted using an automatic blood cell counter (Sysmex, Kobe, Japan).

\subsection{Cell Culture}

hCMEC/D3 cells [66] were cultured in rat-collagen-coated $75 \mathrm{~cm}^{2}$ flasks in Earl's salts-containing Medium 199 supplemented with 10\% (v/v) FCS, 1\% (v/v) streptomycin/penicillin, 1\% $(v / v)$ chemically defined lipid concentrate (ThermoFisher), $1 \%(v / v)$ HEPES buffer, $1.4 \mu \mathrm{M}$ hydrocortisone, $5 \mu \mathrm{g} / \mathrm{mL}$ ascorbic acid, and $1 \mathrm{ng} / \mathrm{mL}$ bovine fibroblast growth factor at $37^{\circ} \mathrm{C}\left(5 \% \mathrm{CO}_{2}\right)$ until confluence. Prior to experiments, cells were serum-starved overnight in Earls salts-containing M199. Only passages below 38 were used for experiments.

\subsection{Gas Chromatography (GC)}

Mouse brain capillary lipids were extracted twice with chloroform/methanol (2:1, v:v) and dried under a stream of nitrogen. After addition of the internal standard (pentadecanoic acid), lipids were trans-esterified $(1.2 \mathrm{~mL}$ toluene and $1 \mathrm{~mL}$ boron trifluoride-methanol $(20 \%))$ at $110{ }^{\circ} \mathrm{C}$ for $1 \mathrm{~h}$. GC analysis of the corresponding FA methyl esters was performed as described [67] and concentrations were quantitated by peak area comparison with the internal standard and normalized to total cell protein concentrations.

\subsection{Liquid Chromatography-Electrospray Ionization-Mass Spectroscopy (LC-ESI-MS/MS)}

Samples were mixed with chloroform/methanol $(2: 1 ; v / v)$ and Cer17:0 and SM17:0 as internal standards (Avanti Polar Lipids, Alabaster, USA). For SL analysis, lipid extracts were subjected to a mild alkaline hydrolysis step by adding $400 \mu \mathrm{L} 1 \mathrm{M} \mathrm{NaOH}$ in chloroform/methanol/ $\mathrm{H}_{2} \mathrm{O}(16: 16: 5, v / v / v)$ and incubated for $45 \mathrm{~min}$ at room temperature. Samples were neutralized (150 $\mu \mathrm{L}$ of $1 \mathrm{M}$ acetic acid, $400 \mu \mathrm{L}$ of $0.5 \mathrm{M}$ EDTA), and $1 \mathrm{~mL} \mathrm{CHCl}_{3}$ was added. Samples were vortexed, centrifuged, and the upper aqueous layer was removed. After a second washing step $\left(700 \mu \mathrm{L} \mathrm{H}_{2} \mathrm{O}\right)$, the organic layer was dried under a gentle stream of nitrogen. Lipids were redissolved in $120 \mu \mathrm{L}$ 2-propanol/methanol/water $(7 / 2.5 / 1, v / v / v)$ for UPLC-MS analysis. Chromatographic separation was modified after Knittelfelder et al. [68] using an ACQUITY-UPLC system (Waters Corporation), equipped with a Luna omega C18 column $(2.1 \times 50 \mathrm{~mm}, 1.6 \mu \mathrm{m}$; Phenomenex) starting a 20 min linear gradient with $80 \%$ solvent $\mathrm{A}$ $(\mathrm{MeOH} / \mathrm{H} 2 \mathrm{O}, 1: 1, v / v ; 10 \mathrm{mM}$ ammonium acetate, $0,1 \%$ formic acid, $8 \mu \mathrm{M}$ phosphoric acid). The column compartment was kept at $50{ }^{\circ} \mathrm{C}$. A EVOQ Elite ${ }^{\mathrm{TM}}$ triple quadrupole mass spectrometer (Bruker) equipped with an ESI source was used for detection of lipids in positive ionization mode. Lipid species were analyzed by selected reaction monitoring (Cer, $[\mathrm{M}+\mathrm{H}]+$ to $\mathrm{m} / \mathrm{z} 264.3,22 \mathrm{eV}, 60 \mathrm{~ms} ; \mathrm{SM},[\mathrm{M}+\mathrm{H}]+$ to $\mathrm{m} / \mathrm{z}$ 184.1, $20 \mathrm{eV}, 40 \mathrm{~ms}$; resolution 0.7 Q1/Q3). Data acquisition was done by MS Workstation (Bruker). Data were normalized for recovery, extraction-, and ionization efficacy by calculating analyte/IS ratios (arbitrary units; AU) and expressed as AU/mg protein. 


\subsection{ELISA}

Wt and $\mathrm{MPO}^{-/-}$mice were injected i.p. with $200 \mu \mathrm{L}$ PBS (controls) or $200 \mu \mathrm{L}$ LPS $(8.3 \mu \mathrm{g}$ in PBS/g body weight \pm MPO inhibitor ABAH (40 $\mu \mathrm{g} / \mathrm{g}$ body weight). After $12 \mathrm{~h}$, blood was collected by submandibular puncture. Serum IL-1 $\beta$, IL-6, and TNF $\alpha$ concentrations were quantitated using mouse ELISAs (Peprotech, Vienna, Austria). For human serum samples ELISAs from ImmunoTools (Friesoythe; Germany) were used. Serum MPO concentrations were determined using a commercial ELISA kit (Abcam, Cambridge, UK). The assays were performed according to manufacturer's instructions. The concentrations of the cytokines were determined using the external standard curve.

\subsection{Electrical Cell-Substrate Impedance Sensing (ECIS)}

Barrier function was determined by impedance monitoring with an (ECIS Z system, Applied Biophysics, Troy, NY, USA). hCMEC/D3 cells were seeded on collagen-coated gold electrodes of 8W10E+ arrays, cultured until confluence and serum-starved overnight prior to the experiment. Impedance was recorded in real time at $1 \mathrm{~min}$ intervals at $4 \mathrm{kHz}$ (barrier function) and $64 \mathrm{kHz}$ (integrity of cell monolayer). Measurements were performed in the presence of $20 \%(v / v)$ serum from non-sepsis or sepsis $( \pm \mathrm{ABAH}, 100 \mu \mathrm{M})$ patients as indicated. Despite the advantage of resembling a human system, this cell line develops lower transendothelial electrical resistance values and displays higher permeability as compared to primary culture models [69].

\subsection{Mitochondrial Respiration Measurement}

Fifty thousand hCMEC/D3 cells were seeded per well in an Agilent Seahorse XF96 Cell Culture Microplate coated with Cell-Tak ${ }^{\mathrm{TM}}$ according to manufacturer's protocol. After 24 h serum-starvation, cells were washed and preincubated for $30 \mathrm{~min}$ in XF assay medium supplemented with sodium pyruvate $(1 \mathrm{mM})$ with or without glutamine $(2 \mathrm{mM})$ and glucose $(25 \mathrm{mM})$ at $37{ }^{\circ} \mathrm{C}$ in a non- $\mathrm{CO}_{2}$ environment. The oxygen consumption rate (OCR) was subsequently measured every $7 \mathrm{~min}$ using an XF96 extracellular flux analyzer (Seahorse Bioscience, North Billerica, MA, USA). A standard protocol with 15 min basal measurement followed by $2 \mu \mathrm{M}$ oligomycin (ATP synthase inhibition), addition of $1 \mu \mathrm{M}$ carbonyl cyanide p-trifluoromethoxy-phenylhydrazone (FCCP; proton gradient disruption), and $2.5 \mu \mathrm{M}$ antimycin A (complexIII inhibition) was applied. Oxygen consumption was normalized to cell number ( $\mathrm{pmol} \mathrm{O}_{2} / \mathrm{min} \times$ number of cells). Samples were measured in sextuplicate.

\subsection{3. qPCR Analysis}

Serum-starved hCMEC/d3 cells were stimulated with $\mathrm{rTNF} \alpha(0.1 \mathrm{ng} / \mathrm{mL}, 1 \mathrm{ng} / \mathrm{mL}, 10 \mathrm{ng} / \mathrm{mL})$ followed by total RNA isolation using the RNeasy Mini Kit (Qiagen, Hilden, Germany). RNA was quantitated by NanoDrop measurements (Thermo Fisher Scientific; Waltham, MA, USA) and reverse-transcribed using the high-capacity cDNA reverse transcription kit (Applied Biosystems; Foster City, CA, USA). qPCR was carried out on an Applied Biosystems 7900HT Fast Real-Time PCR system using Quantifast ${ }^{\mathrm{TM}}$ SYBR Green PCR. Relative gene expression was normalized to hypoxanthine-guanine phosphoribosyltransferase (HPRT). Expression profiles and associated statistical parameters were analyzed by the $2^{-\mathrm{ddCt}}$ method.

\subsection{Statistical Analysis}

All experiments were performed using the appropriate number of replicates per experimental group that is indicated in the respective figure legend. Statistical analyses were performed using the GraphPad Prism version 5 for Mac (GraphPad Software, Inc., San Diego, CA, USA). Testing for normal distribution was performed by the Kolmogorov-Smirnov test (in case of non-normal distribution significance was calculated by Mann-Whitney test). Data obtained from independent measurements were analyzed by one-way ANOVA followed by Bonferroni's post hoc test. For the analysis of two experimental groups, the unpaired Student's $t$-test was used. 
Supplementary Materials: Supplementary materials can be found at http://www.mdpi.com/1422-0067/21/3/1143/ s1.

Author Contributions: M.G., E.B., I.P., H.R., C.L., T.O.E., G.R., C.T.M.-S., and J.P. performed experimental work, M.G., E.B., P.E., W.F.G., D.K., E.M., and W.S. analyzed and interpreted data, M.G., E.B., P.E., E.M. and W.S. designed the study, M.G., E.M., and W.S. wrote the manuscript. All authors have read and agreed to the published version of the manuscript.

Funding: The Austrian Science Fund (FWF; DK MOLIN-W1241, P30882), the Medical University of Graz (PhD program Molecular Medicine), the Austrian National Bank (OENB 17600), and BioTechMed-Graz provided financial support. I.P. was supported by a research fellowship grant from L'Oreal "For Women in Science" and the Austrian Academy of Science (OeAW) and a grant from the Franz Lanyar Foundation (\#411). C.T.M-S. is currently funded by an Erwin Schroedinger Abroad Fellowship (J4205-B27). The funders were not involved in the study design, collection, analysis, and interpretation of data, the writing of the article or the decision to submit for publication.

Acknowledgments: Expert technical assistance by Silvia Rainer, Anja Feiner, and Christopher Trummer is gratefully acknowledged. We thank Isabella Hindler and Arno Absenger for expert mouse care.

Conflicts of Interest: The authors declare no conflict of interest.

\section{Abbreviations}

$\begin{array}{ll}\text { ABAH } & \text { 4-aminobenzoic acid hydrazide } \\ \text { ACER } & \text { Alkaline ceramidase } \\ \text { BBB } & \text { Blood-brain barrier } \\ \text { BMVEC } & \text { Brain microvascular endothelial cells } \\ \text { Cer } & \text { Ceramide } \\ \text { CerS } & \text { Ceramide synthase } \\ \text { CNS } & \text { Central nervous system } \\ \text { EAE } & \text { Experimental autoimmune encephalomyelitis } \\ \text { ECIS } & \text { Electric cell-substrate impedance sensing } \\ \text { FA } & \text { Fatty acid } \\ \text { FCCP } & \text { Carbonyl cyanide-4-(trifluoromethoxy)phenylhydrazone } \\ \text { HOCl } & \text { Hypochlorous acid } \\ \text { HPRT } & \text { Hypoxanthine-guanine phosphoribosyltransferase } \\ \text { LPP } & \text { Lipidphosphate phosphatase } \\ \text { LPS } & \text { Lipopolysaccharide } \\ \text { MPO } & \text { Myeloperoxidase } \\ \text { OCR } & \text { Oxygen consumption rate } \\ \text { RER } & \text { Respiratory exchange ratio } \\ \text { ROS } & \text { Reactive oxygen species } \\ \text { S1P } & \text { Sphingosine-1-phosphate } \\ \text { S1PR } & \text { Sphingosine-1-phosphate receptor } \\ \text { SGMS } & \text { Phosphatidylcholine:ceramide cholinephosphotransferase } \\ \text { SGPP } & \text { Sphingosine-1-phosphate phosphatase } \\ \text { SL } & \text { Sphingolipid } \\ \text { SM } & \text { Sphingomyelin } \\ \text { SMPD } & \text { Sphingomyelin phosphodiesterase } \\ \text { SOFA } & \text { Sepsis-associated organ failure } \\ \text { SPHK } & \text { Serine palmitoyltransferase 1-3 (gene name SPTLC1-3) } \\ \text { SPT1-3 } & \\ \text { SPTSS } & \text { Wt }\end{array}$

\section{References}

1. Obermeier, B.; Daneman, R.; Ransohoff, R.M. Development, maintenance and disruption of the blood-brain barrier. Nat. Med. 2013, 19, 1584-1596. [CrossRef] [PubMed] 
2. Schenk, G.J.; de Vries, H.E. Altered blood-brain barrier transport in neuro-inflammatory disorders. Drug. Discov. Today Technol. 2016, 20, 5-11. [CrossRef] [PubMed]

3. Ben-Zvi, A.; Lacoste, B.; Kur, E.; Andreone, B.J.; Mayshar, Y.; Yan, H.; Gu, C. Mfsd2a is critical for the formation and function of the blood-brain barrier. Nature 2014, 509, 507-511. [CrossRef] [PubMed]

4. Andreone, B.J.; Chow, B.W.; Tata, A.; Lacoste, B.; Ben-Zvi, A.; Bullock, K.; Deik, A.A.; Ginty, D.D.; Clish, C.B.; Gu, C. Blood-Brain Barrier Permeability Is Regulated by Lipid Transport-Dependent Suppression of Caveolae-Mediated Transcytosis. Neuron 2017, 94, 581-594.e5. [CrossRef]

5. Kuperberg, S.J.; Wadgaonkar, R. Sepsis-Associated Encephalopathy: The Blood-Brain Barrier and the Sphingolipid Rheostat. Front. Immunol. 2017, 8, 597. [CrossRef]

6. Hannun, Y.A.; Obeid, L.M. Sphingolipids and their metabolism in physiology and disease. Nat. Rev. Mol. Cell Biol. 2018, 19, 175-191. [CrossRef]

7. Prager, B.; Spampinato, S.F.; Ransohoff, R.M. Sphingosine 1-phosphate signaling at the blood-brain barrier. Trends Mol. Med. 2015, 21, 354-363. [CrossRef]

8. Castillo, S.S.; Levy, M.; Thaikoottathil, J.V.; Goldkorn, T. Reactive nitrogen and oxygen species activate different sphingomyelinases to induce apoptosis in airway epithelial cells. Exp. Cell Res. 2007, 313, 2680-2686. [CrossRef]

9. Rapizzi, E.; Taddei, M.L.; Fiaschi, T.; Donati, C.; Bruni, P.; Chiarugi, P. Sphingosine 1-phosphate increases glucose uptake through trans-activation of insulin receptor. Cell Mol. Life Sci. 2009, 66, 3207-3218. [CrossRef]

10. Jernigan, P.L.; Makley, A.T.; Hoehn, R.S.; Edwards, M.J.; Pritts, T.A. The role of sphingolipids in endothelial barrier function. Biol. Chem. 2015, 396, 681-691. [CrossRef]

11. Vutukuri, R.; Brunkhorst, R.; Kestner, R.I.; Hansen, L.; Ferreiros Bouzas, N.; Pfeilschifter, J.; Devraj, K.; Pfeilschifter, W. Alteration of sphingolipid metabolism as a putative mechanism underlying LPS-induced BBB disruption. J. Neurochem 2017, 144, 172-185. [CrossRef] [PubMed]

12. Ghezzi, P.; Jaquet, V.; Marcucci, F.; Schmidt, H. The oxidative stress theory of disease: Levels of evidence and epistemological aspects. Br. J. Pharmacol 2017, 174, 1784-1796. [CrossRef] [PubMed]

13. Ristow, M.; Schmeisser, S. Extending life span by increasing oxidative stress. Free Radic Biol. Med. 2011, 51, 327-336. [CrossRef] [PubMed]

14. Patel, M. Targeting Oxidative Stress in Central Nervous System Disorders. Trends Pharmacol. Sci. 2016, 37, 768-778. [CrossRef] [PubMed]

15. Schmidt, H.H.; Stocker, R.; Vollbracht, C.; Paulsen, G.; Riley, D.; Daiber, A.; Cuadrado, A. Antioxidants in Translational Medicine. Antioxid. Redox Signal. 2015, 23, 1130-1143. [CrossRef]

16. Casas, A.I.; Dao, V.T.; Daiber, A.; Maghzal, G.J.; Di Lisa, F.; Kaludercic, N.; Leach, S.; Cuadrado, A.; Jaquet, V.; Seredenina, T.; et al. Reactive Oxygen-Related Diseases: Therapeutic Targets and Emerging Clinical Indications. Antioxid. Redox Signal. 2015, 23, 1171-1185. [CrossRef]

17. Klebanoff, S.J. Myeloperoxidase: Friend and foe. J. Leukoc. Biol. 2005, 77, 598-625. [CrossRef]

18. Palladino, E.N.D.; Hartman, C.L.; Albert, C.J.; Ford, D.A. The chlorinated lipidome originating from myeloperoxidase-derived $\mathrm{HOCl}$ targeting plasmalogens: Metabolism, clearance, and biological properties. Arch. Biochem. Biophys. 2018, 641, 31-38. [CrossRef]

19. Brahmbhatt, V.V.; Hsu, F.F.; Kao, J.L.; Frank, E.C.; Ford, D.A. Novel carbonyl and nitrile products from reactive chlorinating species attack of lysosphingolipid. Chem. Phys. Lipids 2007, 145, 72-84. [CrossRef]

20. Nusshold, C.; Kollroser, M.; Kofeler, H.; Rechberger, G.; Reicher, H.; Ullen, A.; Bernhart, E.; Waltl, S.; Kratzer, I.; Hermetter, A.; et al. Hypochlorite modification of sphingomyelin generates chlorinated lipid species that induce apoptosis and proteome alterations in dopaminergic PC12 neurons in vitro. Free Radic Biol. Med. 2010, 48, 1588-1600. [CrossRef]

21. Lewis, A.J.; Seymour, C.W.; Rosengart, M.R. Current Murine Models of Sepsis. Surg. Infect. (Larchmt) 2016, 17, 385-393. [CrossRef] [PubMed]

22. Bhat, O.M.; Yuan, X.; Li, G.; Lee, R.; Li, P.L. Sphingolipids and Redox Signaling in Renal Regulation and Chronic Kidney Diseases. Antioxid. Redox Signal. 2018. [CrossRef] [PubMed]

23. Dantzer, R.; O'Connor, J.C.; Freund, G.G.; Johnson, R.W.; Kelley, K.W. From inflammation to sickness and depression: When the immune system subjugates the brain. Nat. Rev. Neurosci 2008, 9, 46-56. [CrossRef] [PubMed]

24. Maki, R.A.; Holzer, M.; Motamedchaboki, K.; Malle, E.; Masliah, E.; Marsche, G.; Reynolds, W.F. Human myeloperoxidase (hMPO) is expressed in neurons in the substantia nigra in Parkinson's disease and in 
the hMPO-alpha-synuclein-A53T mouse model, correlating with increased nitration and aggregation of alpha-synuclein and exacerbation of motor impairment. Free Radic Biol. Med. 2019, 141, 115-140.

25. Kalogiannis, M.; Delikatny, E.J.; Jeitner, T.M. Serotonin as a putative scavenger of hypohalous acid in the brain. BBA 2016, 1862, 651-661. [CrossRef]

26. Becher, B.; Spath, S.; Goverman, J. Cytokine networks in neuroinflammation. Nat. Rev. Immunol. 2017, 17, 49-59. [CrossRef]

27. Boveri, M.; Kinsner, A.; Berezowski, V.; Lenfant, A.M.; Draing, C.; Cecchelli, R.; Dehouck, M.P.; Hartung, T.; Prieto, P.; Bal-Price, A. Highly purified lipoteichoic acid from gram-positive bacteria induces in vitro blood-brain barrier disruption through glia activation: Role of pro-inflammatory cytokines and nitric oxide. Neuroscience 2006, 137, 1193-1209. [CrossRef]

28. Doll, D.N.; Hu, H.; Sun, J.; Lewis, S.E.; Simpkins, J.W.; Ren, X. Mitochondrial crisis in cerebrovascular endothelial cells opens the blood-brain barrier. Stroke 2015, 46, 1681-1689. [CrossRef]

29. Yu, G.; Liang, Y.; Huang, Z.; Jones, D.W.; Pritchard, K.A., Jr.; Zhang, H. Inhibition of myeloperoxidase oxidant production by $\mathrm{N}$-acetyl lysyltyrosylcysteine amide reduces brain damage in a murine model of stroke. J. Neuroinflamm. 2016, 13, 119. [CrossRef]

30. Yu, G.; Zheng, S.; Liang, Y.; Zhang, H. Inhibition of myeloperoxidase by N-acetyl lysyltyrosylcysteine amide reduces oxidative stress-mediated inflammation, neuronal damage, and neural stem cell injury in a murine model of stroke. J. Pharmacol. Exp. Ther. 2017, 364,311-322. [CrossRef]

31. Zhang, H.; Ray, A.; Miller, N.M.; Hartwig, D.; Pritchard, K.A., Jr.; Dittel, B.N. Inhibition of Myeloperoxidase at the Peak of Experimental Autoimmune Encephalomyelitis Restores Blood-Brain-Barrier Integrity and Ameliorates Disease Severity. J. Neurochem. 2015, 136, 826-836. [CrossRef] [PubMed]

32. Haddadi, R.; Mohajjel Nayebi, A.; Brooshghalan, S.E. Pre-treatment with silymarin reduces brain myeloperoxidase activity and inflammatory cytokines in 6-OHDA hemi-parkinsonian rats. Neurosci. Lett. 2013, 555, 106-111. [CrossRef] [PubMed]

33. Kim, H.; Wei, Y.; Lee, J.Y.; Wu, Y.; Zheng, Y.; Moskowitz, M.A.; Chen, J.W. Myeloperoxidase Inhibition Increases Neurogenesis after Ischemic Stroke. J. Pharmacol. Exp. Ther. 2016, 359, 262-272. [CrossRef] [PubMed]

34. Forghani, R.; Kim, H.J.; Wojtkiewicz, G.R.; Bure, L.; Wu, Y.; Hayase, M.; Wei, Y.; Zheng, Y.; Moskowitz, M.A.; Chen, J.W. Myeloperoxidase propagates damage and is a potential therapeutic target for subacute stroke. J. Cereb. Blood Flow Metab. 2015, 35, 485-493. [CrossRef]

35. Kubota, K.; Saiwai, H.; Kumamaru, H.; Maeda, T.; Ohkawa, Y.; Aratani, Y.; Nagano, T.; Iwamoto, Y.; Okada, S. Myeloperoxidase exacerbates secondary injury by generating highly reactive oxygen species and mediating neutrophil recruitment in experimental spinal cord injury. Spine (Phila Pa 1976) 2012, 37, 1363-1369. [CrossRef]

36. Ullen, A.; Singewald, E.; Konya, V.; Fauler, G.; Reicher, H.; Nusshold, C.; Hammer, A.; Kratky, D.; Heinemann, A.; Holzer, P.; et al. Myeloperoxidase-derived oxidants induce blood-brain barrier dysfunction in vitro and in vivo. PLoS ONE 2013, 8, e64034. [CrossRef]

37. Phuah, C.L.; Dave, T.; Malik, R.; Raffeld, M.R.; Ayres, A.M.; Goldstein, J.N.; Viswanathan, A.; Greenberg, S.M.; Jagiella, J.M.; Hansen, B.M.; et al. Genetic variants influencing elevated myeloperoxidase levels increase risk of stroke. Brain 2017, 140, 2663-2672. [CrossRef]

38. Meyer, N.J.; Reilly, J.P.; Feng, R.; Christie, J.D.; Hazen, S.L.; Albert, C.J.; Franke, J.D.; Hartman, C.L.; McHowat, J.; Ford, D.A. Myeloperoxidase-derived 2-chlorofatty acids contribute to human sepsis mortality via acute respiratory distress syndrome. JCI Insight 2017, 2, e96432. [CrossRef]

39. Brown, K.A.; Brain, S.D.; Pearson, J.D.; Edgeworth, J.D.; Lewis, S.M.; Treacher, D.F. Neutrophils in development of multiple organ failure in sepsis. Lancet 2006, 368, 157-169. [CrossRef]

40. Carr, A.C.; Spencer, E.; Hoskin, T.S.; Rosengrave, P.; Kettle, A.J.; Shaw, G. Circulating myeloperoxidase is elevated in septic shock and is associated with systemic organ failure and mortality in critically ill patients. Free Radic. Biol. Med. 2019, S0891-5849(19)31559-X. [CrossRef]

41. Demaret, J.; Venet, F.; Friggeri, A.; Cazalis, M.A.; Plassais, J.; Jallades, L.; Malcus, C.; Poitevin-Later, F.; Textoris, J.; Lepape, A.; et al. Marked alterations of neutrophil functions during sepsis-induced immunosuppression. J. Leukoc. Biol. 2015, 98, 1081-1090. [CrossRef] [PubMed] 
42. Reber, L.L.; Gillis, C.M.; Starkl, P.; Jonsson, F.; Sibilano, R.; Marichal, T.; Gaudenzio, N.; Berard, M.; Rogalla, S.; Contag, C.H.; et al. Neutrophil myeloperoxidase diminishes the toxic effects and mortality induced by lipopolysaccharide. J. Exp. Med. 2017, 214, 1249-1258. [CrossRef] [PubMed]

43. Liu, Z.; Liu, W.; Huang, Y.; Guo, J.; Zhao, R.; Yang, X. Lipopolysaccharide significantly influences the hepatic triglyceride metabolism in growing pigs. Lipids Health Dis. 2015, 14, 64. [CrossRef] [PubMed]

44. Feingold, K.R.; Staprans, I.; Memon, R.A.; Moser, A.H.; Shigenaga, J.K.; Doerrler, W.; Dinarello, C.A.; Grunfeld, C. Endotoxin rapidly induces changes in lipid metabolism that produce hypertriglyceridemia: Low doses stimulate hepatic triglyceride production while high doses inhibit clearance. J. Lipid Res. 1992, 33, 1765-1776. [PubMed]

45. Khovidhunkit, W.; Kim, M.S.; Memon, R.A.; Shigenaga, J.K.; Moser, A.H.; Feingold, K.R.; Grunfeld, C. Effects of infection and inflammation on lipid and lipoprotein metabolism: Mechanisms and consequences to the host. J. Lipid Res. 2004, 45, 1169-1196. [CrossRef]

46. Brown, J.A.; Codreanu, S.G.; Shi, M.; Sherrod, S.D.; Markov, D.A.; Neely, M.D.; Britt, C.M.; Hoilett, O.S.; Reiserer, R.S.; Samson, P.C.; et al. Metabolic consequences of inflammatory disruption of the blood-brain barrier in an organ-on-chip model of the human neurovascular unit. J. Neuroinflamm. 2016, 13, 306. [CrossRef]

47. Clarke, C.J.; Truong, T.G.; Hannun, Y.A. Role for neutral sphingomyelinase-2 in tumor necrosis factor alpha-stimulated expression of vascular cell adhesion molecule-1 (VCAM) and intercellular adhesion molecule-1 (ICAM) in lung epithelial cells: p38 MAPK is an upstream regulator of nSMase2. J. Biol. Chem. 2007, 282, 1384-1396. [CrossRef]

48. Thukkani, A.K.; McHowat, J.; Hsu, F.F.; Brennan, M.L.; Hazen, S.L.; Ford, D.A. Identification of alpha-chloro fatty aldehydes and unsaturated lysophosphatidylcholine molecular species in human atherosclerotic lesions. Circulation 2003, 108, 3128-3133. [CrossRef]

49. Thukkani, A.K.; Martinson, B.D.; Albert, C.J.; Vogler, G.A.; Ford, D.A. Neutrophil-mediated accumulation of 2-ClHDA during myocardial infarction: 2-ClHDA-mediated myocardial injury. Am. J. Physiol. Heart Circ. Physiol. 2005, 288, H2955-H2964. [CrossRef]

50. Ullen, A.; Fauler, G.; Kofeler, H.; Waltl, S.; Nusshold, C.; Bernhart, E.; Reicher, H.; Leis, H.J.; Wintersperger, A.; Malle, E.; et al. Mouse brain plasmalogens are targets for hypochlorous acid-mediated modification in vitro and in vivo. Free Radic Biol. Med. 2010, 49, 1655-1665. [CrossRef]

51. Shadyro, O.; Lisovskaya, A.; Semenkova, G.; Edimecheva, I.; Amaegberi, N. Free-radical Destruction of Sphingolipids Resulting in 2-hexadecenal Formation. Lipid Insights 2015, 8, 1-9. [CrossRef] [PubMed]

52. Haegens, A.; Heeringa, P.; van Suylen, R.J.; Steele, C.; Aratani, Y.; O’Donoghue, R.J.; Mutsaers, S.E.; Mossman, B.T.; Wouters, E.F.; Vernooy, J.H. Myeloperoxidase deficiency attenuates lipopolysaccharideinduced acute lung inflammation and subsequent cytokine and chemokine production. J. Immunol. 2009, 182, 7990-7996. [CrossRef] [PubMed]

53. Jeitner, T.M.; Kalogiannis, M.; Krasnikov, B.F.; Gomolin, I.; Peltier, M.R.; Moran, G.R. Linking Inflammation and Parkinson Disease: Hypochlorous Acid Generates Parkinsonian Poisons. Toxicol. Sci. 2016, 151, 388-402. [CrossRef] [PubMed]

54. Samanta, S.; Govindaraju, T. Unambiguous Detection of Elevated Levels of Hypochlorous Acid in APP/PS1 Mouse Brain. ACS Chem. Neurosci. 2019, 10, 4847-4853. [CrossRef] [PubMed]

55. Alexander, J.J.; Jacob, A.; Cunningham, P.; Hensley, L.; Quigg, R.J. TNF is a key mediator of septic encephalopathy acting through its receptor, TNF receptor-1. Neurochem. Int. 2008, 52, 447-456. [CrossRef] [PubMed]

56. Mantle, J.L.; Lee, K.H. A differentiating neural stem cell-derived astrocytic population mitigates the inflammatory effects of TNF-alpha and IL-6 in an iPSC-based blood-brain barrier model. Neurobiol. Dis. 2018, 119, 113-120. [CrossRef]

57. Cheng, Y.; Desse, S.; Martinez, A.; Worthen, R.J.; Jope, R.S.; Beurel, E. TNFalpha disrupts blood brain barrier integrity to maintain prolonged depressive-like behavior in mice. Brain Behav. Immun. 2018, 69, 556-567. [CrossRef]

58. Wegner, M.S.; Schiffmann, S.; Parnham, M.J.; Geisslinger, G.; Grosch, S. The enigma of ceramide synthase regulation in mammalian cells. Prog. Lipid Res. 2016, 63, 93-119. [CrossRef]

59. Chan, R.B.; Oliveira, T.G.; Cortes, E.P.; Honig, L.S.; Duff, K.E.; Small, S.A.; Wenk, M.R.; Shui, G.; Di Paolo, G. Comparative lipidomic analysis of mouse and human brain with Alzheimer disease. J. Biol. Chem. 2012, 287, 2678-2688. [CrossRef] 
60. Alvarez, S.E.; Harikumar, K.B.; Hait, N.C.; Allegood, J.; Strub, G.M.; Kim, E.Y.; Maceyka, M.; Jiang, H.; Luo, C.; Kordula, T.; et al. Sphingosine-1-phosphate is a missing cofactor for the E3 ubiquitin ligase TRAF2. Nature 2010, 465, 1084-1088. [CrossRef]

61. Danielski, L.G.; Giustina, A.D.; Badawy, M.; Barichello, T.; Quevedo, J.; Dal-Pizzol, F.; Petronilho, F. Brain Barrier Breakdown as a Cause and Consequence of Neuroinflammation in Sepsis. Mol. Neurobiol. 2018, 55, 1045-1053. [CrossRef] [PubMed]

62. Hernandez-Corbacho, M.J.; Salama, M.F.; Canals, D.; Senkal, C.E.; Obeid, L.M. Sphingolipids in mitochondria. Biochim. Biophys. Acta Mol. Cell. Biol. Lipids 2017, 1862, 56-68. [CrossRef] [PubMed]

63. Schwartz, N.U.; Linzer, R.W.; Truman, J.P.; Gurevich, M.; Hannun, Y.A.; Senkal, C.E.; Obeid, L.M. Decreased ceramide underlies mitochondrial dysfunction in Charcot-Marie-Tooth 2F. FASEB J. 2018, 32, 1716-1728. [CrossRef] [PubMed]

64. Ullen, A.; Fauler, G.; Bernhart, E.; Nusshold, C.; Reicher, H.; Leis, H.J.; Malle, E.; Sattler, W. Phloretin ameliorates 2-chlorohexadecanal-mediated brain microvascular endothelial cell dysfunction in vitro. Free Radic Biol. Med. 2012, 53, 1770-1781. [CrossRef]

65. Singer, M.; Deutschman, C.S.; Seymour, C.W.; Shankar-Hari, M.; Annane, D.; Bauer, M.; Bellomo, R.; Bernard, G.R.; Chiche, J.D.; Coopersmith, C.M.; et al. The Third International Consensus Definitions for Sepsis and Septic Shock (Sepsis-3). JAMA 2016, 315, 801-810. [CrossRef]

66. Nusshold, C.; Ullen, A.; Kogelnik, N.; Bernhart, E.; Reicher, H.; Plastira, I.; Glasnov, T.; Zangger, K.; Rechberger, G.; Kollroser, M.; et al. Assessment of electrophile damage in a human brain endothelial cell line utilizing a clickable alkyne analog of 2-chlorohexadecanal. Free Radic Biol. Med. 2016, 90, 59-74. [CrossRef]

67. Sattler, W.; Puhl, H.; Hayn, M.; Kostner, G.M.; Esterbauer, H. Determination of fatty acids in the main lipoprotein classes by capillary gas chromatography: BF3/methanol transesterification of lyophilized samples instead of Folch extraction gives higher yields. Anal. Biochem. 1991, 198, 184-190. [CrossRef]

68. Knittelfelder, O.L.; Weberhofer, B.P.; Eichmann, T.O.; Kohlwein, S.D.; Rechberger, G.N. A versatile ultra-high performance LC-MS method for lipid profiling. J. Chromatogr. B Anal. Technol. Biomed. Life Sci. 2014, 951-952, 119-128. [CrossRef]

69. Weksler, B.B.; Subileau, E.A.; Perriere, N.; Charneau, P.; Holloway, K.; Leveque, M.; Tricoire-Leignel, H.; Nicotra, A.; Bourdoulous, S.; Turowski, P.; et al. Blood-brain barrier-specific properties of a human adult brain endothelial cell line. FASEB J. 2005, 19, 1872-1874. [CrossRef] 